\title{
Adopting collaborative games into Open Kanban
}

\author{
Adam Przybyłek, Marcin K. Olszewski \\ Gdansk University of Technology, Faculty of Electronics, Telecommunications and Informatics \\ Narutowicza 11/12, 80-233 Gdańsk, Poland \\ Email: adam.przybylek@gmail.com,marolszak@vp.pl
}

\begin{abstract}
The crucial element of any agile project is people. Not surprisingly, principles and values such as "Respect for people", "Communication and Collaboration", "Lead using a team approach", and "Learn and improve continuously" are an integral part of Open Kanban. However, Open Kanban has not provided any tools or techniques to aid the human side of software development. Moreover, as a Lean initiative, it is not as comprehensively defined process as Scrum or XP. Accordingly, inexperienced Kanban teams may feel a bit lost. To deal with these challenges, we propose an extension to Open Kanban, which contains a set of 12 collaborative games. The feedback received from three Kanban teams who leveraged our extension in commercial projects, indicates that the adopted games improved participants' communication, commitment, motivation and creativity.
\end{abstract}

\section{INTRODUCTION}

$\mathrm{I}^{\mathrm{N}}$ $\mathrm{N}$ more recent years, the software industry has started to look at Lean as a new approach that could complement Agile Software Development [16]. Lean is a general term for finding ways to eliminate waste and increase efficiency [13]. One of the agile methodologies that adds a vast Lean heritage is Open Kanban [11]. The distinguished characteristics of Open Kanban are: (1) visualization of the workflow with Kanban board, (2) limitation of the work in progress (WIP), and (3) measurement of the lead time [15]. The motivation behind visualization and limiting WIP was to identify the constraints of the process and let each member of a team focus on a single item at a time [1]. This technique promotes the pull approach, which means that the team "pull" work when they are ready, rather than having it "pushed" in from the outside [14].

In contrast to other agile methodologies, Open Kanban leaves almost everything open. It does not prescribe iterations, it does not define roles or meetings, and finally, it does not contain process artifacts [14], [15]. Moreover, although Open Kanban emphasizes the human factor of software development and its founding declaration states that "without teamwork Kanban fails" [11], it does not provide any tools or techniques to aid the human side of software development. Accordingly, inexperienced Kanban teams may feel a bit lost.

Fortunately, Open Kanban can be extended by organizations that wish to create an Agile and Lean method that is customized for their particular audience. We took this opportunity to equip our teams with a set of collaborative games, structured as an extension to Open Kanban. Our research was inspired by the ActiveAction workshop [17], which combines classical and game-based techniques to foster stakeholders' involvement and collaborative identification of objectives and risks.

\section{RESEARCH METHOD}

Our study was conducted as Action Research (AR). In $\mathrm{AR}$, the researcher works in close collaboration with a group of practitioners, acting as a facilitator, to solve a real-world problem while simultaneously studying the experience of solving the problem [5]. The researcher brings his knowledge of action research while the participants bring their practical knowledge and context [3]. The goal of AR is to improve practical matters as well as to improve scientific knowledge [3]. A precondition for action research is to have a problem owner willing to collaborate to both identify a problem, and engage in an effort to solve it. The problem owner in this research was a software development department of a world wide aviation IT provider (the company wishes to remain anonymous). The department experienced typical challenges of adopting a new methodology (i.e. Open Kanban). Its authorities were open to new ideas and willing to implement collaborative games. Three teams that participated in our research are presented in Table I.

TABLE I.

PARTICIPATING TEAMS

\begin{tabular}{|l|l|}
\hline Team & \multicolumn{1}{c|}{ Comments } \\
\hline $\begin{array}{l}\text { T1, } \\
\text { people }\end{array}$ & $\begin{array}{l}\text { The multicultural team of junior developers who provided } \\
\text { services for external customers. All team members were } \\
\text { familiar with Open Kanban. }\end{array}$ \\
\hline $\begin{array}{l}\text { T2, } \\
8-10\end{array}$ & $\begin{array}{l}\text { The team of developers and testers guided by an agile coach. } \\
\text { They developed solutions for internal departments. All team } \\
\text { people } \\
\text { members had over 6 months of experience with agile }\end{array}$ \\
\hline $\begin{array}{l}\text { T3, } \\
6-8 \\
\text { people }\end{array}$ & $\begin{array}{l}\text { The distributed team of instructors with an extensive } \\
\text { experience in programming or project management. They } \\
\text { worked on a project designed to train engineers within the } \\
\text { company. All team members were experienced with Agile } \\
\text { practices, but they got started with Open Kanban. }\end{array}$ \\
\hline
\end{tabular}

\section{IDENTIFICATION OF DEFICIENCIES}

Action Research assumes that theory and practice can be closely integrated by learning from the results of intervention 
that is planned after a thorough diagnosis of the problem context [5]. To identify deficiencies in the adoption of Open Kanban, we prepared a survey that contained a total of 13 questions (Fig. 1). Respondents rated, on a Likert scale of 5 points, their degree of agreement regarding the implementation of Kanban values and practices in their teams. In total, 18 respondents from 3 teams (T1, T2, T3) completed the survey. The respondents were also asked to provide their free comments on the usage of Open Kanban by their organization. The survey was anonymous, so we assumed that the responses were honest.

It is not accidental that "Plan-Do-Check-Act cycle", "Systematic approach to improvement", and "Collecting feedback on the process" received the lowest rates. Open Kanban does not define retrospective meetings, nor does it prescribe timeboxed iterations. Thereby, the investigated teams had practiced only occasional retrospectives.

In the open-ended comment question a few respondents mentioned that their team had problems with complex work items. Indeed, in Open Kanban, no particular item size is prescribed. Since there is no requirement to break down items so they are small enough to fit into a specific time box, the management of the workflow is cumbersome. The results of the survey also suggest that the respondents were familiar with Open Kanban, but their knowledge was incomplete (most of them were neutral on "Understanding of Kanban mechanisms"). Besides, "Work-In-Progress limits" scored slightly above 0 , so the limits probably needed adjustment. Furthermore, the detailed results show that only half of the respondents reported communication between team members as satisfactory.

\section{OUR EXTENSION TO OPEN KANBAN}

For each deficiency identified in the previous section, we suggest collaborative games that might be a remedy for it. Collaborative games refer to several structured techniques inspired by game play and designed to facilitate collaboration, foster customer involvement, and stimulate creative thinking [12]. Fig. 1 presents the mapping between the problematic issues and Open Kanban principles with collaborative games superimposed. The following subsections explain how we intend to enrich Open Kanban by our extension.

\section{A. Visualize the workflow}

Although the teams used a Kanban Board to visualize work, different work item types, and WIP limits, we found room for improvement. Work items were not estimated. As a consequence, it was difficult to manage the workflow and make commitments. Therefore, we set the rule that a work item could not make its way from the backlog onto the board until it had been estimated with Planning poker [9].

\section{B. Learn and improve continuously}

Before our research went into work, every time someone saw an issue which seemed worth reviewing, the team started an ad-hoc kaizen meeting. However, Kanban suggests to make incremental improvements to the existing processes at regular intervals called cadences. Accordingly, during our research we chose a four weeks cadence for retrospectives. A key element of a retrospective is that the team must agree, together, to trust each other and to believe that every comment or suggestion is intended for the sole purpose of improving the team's performance [12]. We expected that collaborative games would make the team feel safe to discuss any issue that concerns them.

The Snake Game stimulates memories and helps the team to gather data from many perspectives [6]. Its objective is to create a shared picture of what has happened since the last retrospective. Participants write sticky notes to represent memorable, personally meaningful events and then post them in chronological order on a large poster of a snake. The more recent the event is, the closer to the head it should be posted. The collected notes can constitute an input to other games for retrospectives.

The Perfection Game [www.mccarthyshow.com/online] is a tool for continuous improvement of the process, team and organization. With this game team members are invited to participate in improvements as they give feedback to each other. To get feedback, team members are asked to: rate (on a scale of 1 to 10) the action, process, item or event being considered; state what they like; suggest what to do to make it perfect. Participants can only withhold points if they provide suggestions to improve the considered issue. If they cannot say how to make it better, the default score is a 10. If participants give a high rating then they have to state what went good, what makes it so good, where does the value come from, etc. Since participants have to motivate their ratings (the rating is coupled to what participants like about it and what they think can be done to do it better), the quality of the feedback is improved.

The Coaching Cards Game uses a deck of colorful cards with various images to represent team members' feelings. At the beginning of each round, each participant chooses one card that illustrates his feelings related to the event being considered. Then, the team discusses their feelings. The game creates a non-threatening opportunity to gather data about feelings during the last release cycle by connecting the feelings to events that happened in the cycle [7]. Even though someone does not want to express his opinion directly, the game allows the team to gather the opinion indirectly. With this game, the team can identify events that provide benefits and events that cause problems.

The Sailboat Game [7] lets a team think about their impediments, risks, good practices, and where they go as a team. The game starts by drawing a sailboat, rocks, wind, and an island. The island represents the team's objectives/vision. The rocks represent the risks the team 
might encounter along the way. The anchor on the boat is everything that slows them down on their journey. The wind represent everything that helps them to reach their objectives [7]. Next, participants write ideas on sticky notes and then post the ideas into the different areas according to the picture. Then, the team discusses how to continue the practices that are written on the clouds/wind area, how to mitigate the identified risks, and what actions can be taken to fix the problems.

\section{Limit Work-in-Progress}

Open Kanban advices limiting the WIP so as to optimize the workflow of the system in accordance with its capacity [11]. A limit on WIP constrains how many work items can be in each workflow step at a time [2]. Limiting the WIP has two major benefits: it reduces the time it takes to get any one thing done (lead time); and it improves quality by giving greater focus to fewer tasks [13]. We suggest two games that demonstrate this principle to new teams.

The Ball Flow Game [availagility.co.uk/2010/11/17/theball-flow-game]. The aim of this game is to pass as many balls as possible through the team in 2 minutes. However, the activity is constrained by the following rules: (1) balls cannot be passed to a direct neighbor (the team arrange themselves in a circle); (2) each ball must be touched at least once by every player; (3) each ball must have air-time as it is passed between players; (4) each ball must return to the same player who introduced it into the system; and (5) if a ball drops, it cannot be picked up. The game is played a total of 3 times with 1-minute breaks in between to inspect and adapt the process. Before each round, the team estimates of how many balls they can pass through the system. In addition, the team has two minutes of preparation time for the first round to self organize and discuss the strategy. The game demonstrates that every system has a natural velocity and to improve the system significantly, it is often not a case of working harder, but a case of changing the process. Players will find out that when balls are pushed into the system, it results in dropped balls and decreases performance. Therefore, they will arrange a pull system - i.e. a system where the balls are not passed until the downstream player is ready.

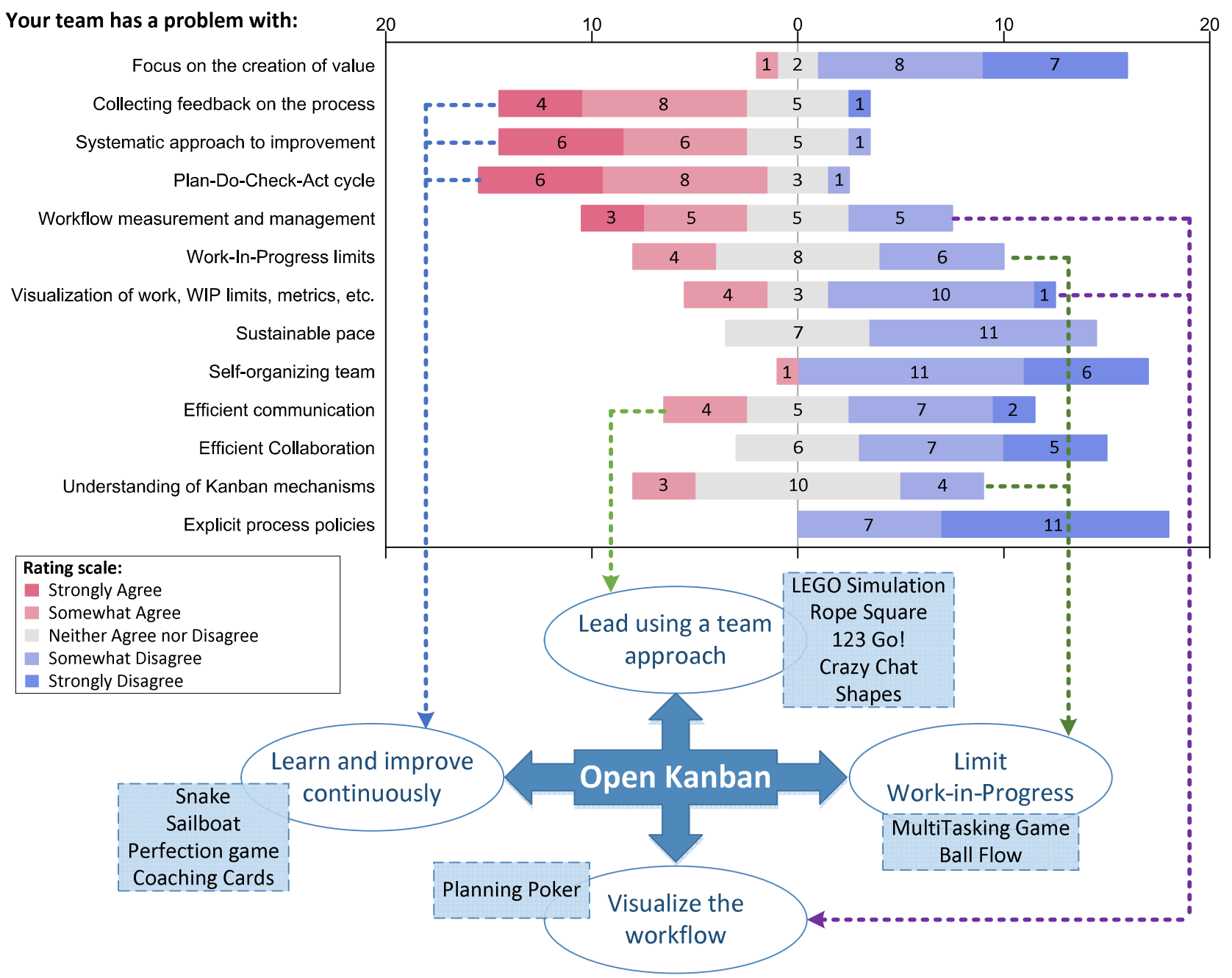

Fig. 1 Summary of questionnaire responses and the proposed extension 
The Number Multitasking Game [10] illustrates the effect of multi-tasking and context switching. It consists of two rounds. In each round, each participant is given a page divided into three columns. The task is to fill out the left column with the Roman numerals I through X, the middle column with the letters A through $\mathrm{J}$, and the right column with the Arabic numerals 1 through 10. In the first round, the participants are asked to write row by row, while in the second round, they are asked to work column by column. The game shows why limited WIP improves lead times and lets developers understand Kanban better.

\section{Lead using a team approach}

Building successful teams and team leadership are crucial to deliver value. At the center of teamwork are effective collaboration and communication. We suggest playing Rope Square and LEGO Simulation as a means of team building and a way to socialize. Besides, these games entail collaboration in decision-making. Other games in this section emphasize the importance of communication.

The Rope Square Game [4] is an icebreaker for team building. The team has to form a perfect square with the rope. Each member must be blindfold and grab the rope with both hands. When the team feels like they are finished and all agree that the rope is in a perfect square, they put the rope to the ground. The game reveals how people fulfill different roles in a group. It also allows the team to build cooperation and trust between members.

LEGO Simulation. The team's task is to build a space base on Mars with LEGO bricks. The facilitator plays the role of the Product Owner. He writes stories, is available to answer questions and to provide feedback. The game encourages the team to communicate with the Product Owner, work in cooperation and reach a consensus.

The 123-go! Game. In this game [8], the facilitator explains that after he counts to three and says "go", everyone should clap their hands. The task for the facilitator is to count to three slowly then clap his hands, pause for a second and say "go". Usually, people will clap when the facilitator claps, rather than when he says "go". This game emphasizes the importance of listening before acting when working in a team.

The Crazy Chat Game teaches players to be more aware of the importance of paying attention. The team split themselves into pairs. Then, for one minute one person talks about something he is most passionate about in life. The other person has to act as disinterested as possible. After a minute they should switch roles.

The Shapes Game. This game teaches that the way we communicate impacts our ability to succeed. The team has to form pairs. Each pair decides who will draw and who will instruct. The instructor is given a picture with shapes. The drawer can not see the shapes or ask any questions. The instructor has to describe the picture giving only verbal instructions, while the drawer has to reproduce the original shapes. The instructor can see what the drawer is doing and provide feedback.

\section{V.EVALUATION AND RESULTS}

The evaluation took place in 2015 and 2016. All games presented in Section IV were implemented in both the T1 and T2 teams. In addition, Planning Poker, Coaching Cards, Perfection Game, Rope square, and Tennis Balls were implemented in the T3 team. The implementation of each game was planned with Agile Coach, Service Leader, or Project Manager.

After each game session, we issued a questionnaire. The participants were asked to indicate their level of agreement with statements about game-playing activity. The responses were on a Likert scale of 1 to 5 (Table II). At the end of the survey, the participants were also invited to specify any additional remarks. We used two different sets of questions one for the retrospective games and Planning Poker (games A), the other for the remaining games (games B). For each game and question, we first took the average per team, and then the average of the averages (the detailed charts are available on http://przybylek.wzr.pl/FedCSIS16). The differences in averages between teams were always less than 1 point, except for Coaching Cards and LEGO Simulation.

Games A aim to directly support teams in their work and were perceived positively. Note, that Planning Poker got a low score in "fostering creativity", but it is not a downside because this game has different objectives. All participants appreciated this game and wanted to use it on a regular basis. Among the retrospective games, Sailboat performed the best but should be used interchangeably with the Perfection game as suggested by a few respondents. Indeed, teams should have a set of possible games to avoid monotony that leads to fatigue and a lack of motivation. In turn, Coaching Cards was not appreciated by the $\mathrm{T} 1$ team. They rated the game lower than both other teams and commented that they did not feel comfortable enough to share their problems, opinions and concerns. In addition, someone mentioned that the results strongly depend on the openness and honesty of participants. Surprisingly, only 2 persons in both the T1 and T2 teams wanted to use the Snake game in the future, even though the game obtained high scores in improving commitment and communication.

Games B make teams aware of some of the key Kanban values or mechanisms and generally should be played only once by each team. According to the comments received, these games should be used during training sessions. Note, that the 123-Go! and Crazy Chat game were carried out during one meeting and jointly evaluated due to their common purpose. Although some games received low scores in certain aspects, this is not a downside because they still meet their objectives. For instance, everyone strongly agreed that Shapes, 123-Go! and Crazy Chat revealed the importance of effective communication. In turn, Number Multitasking demonstrated the cost of context switching. 
TABLE II.

SUMMARY RESULTS

\begin{tabular}{|c|c|c|c|c|c|c|c|c|c|c|c|}
\hline \multirow[b]{2}{*}{$\begin{array}{c}\text { Rating scale: } \\
1 \text { (Strongly disagree) } \\
2 \text { (Disagree) } \\
3 \text { (Neutral) } \\
4 \text { (Agree) } \\
5 \text { (Strongly Agree) }\end{array}$} & \multicolumn{5}{|c|}{ Games A } & \multicolumn{6}{|c|}{ Games B } \\
\hline & 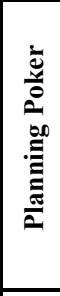 & 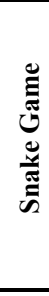 & 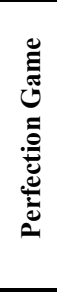 & $\bigcup_{0=0}^{0}$ & 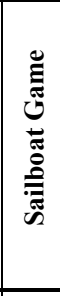 & $\frac{\vec{z}}{\overline{0}}$ & 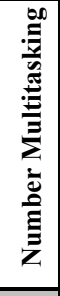 & 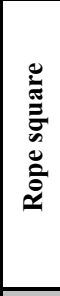 & 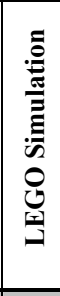 & 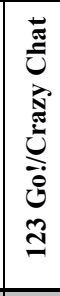 & 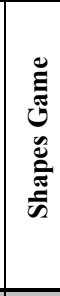 \\
\hline - produces better results than the standard approach & 4,6 & 3,2 & 4,7 & 3,5 & 4,6 & & & & & & \\
\hline - should be implemented permanently instead of the standard approach & 4,2 & 3,0 & 4,7 & 2,5 & 4,7 & & & & & & \\
\hline - may be considered as complementary to the standard approach & 2,7 & 3,2 & 4,7 & 4,3 & 4,4 & & & & & & \\
\hline - fosters participants' creativity & 2,4 & 4,0 & 3,5 & 4,5 & 4,3 & & & & & & \\
\hline - fosters participants' commitment and motivation & 4,3 & 4,5 & 4,0 & 3,2 & 4,6 & & & & & & \\
\hline - improves participants' communication & 4,8 & 4,6 & 3,0 & 3,5 & 4,7 & & & & & & \\
\hline - is easy to understand and play & 4,9 & 5,0 & 4,9 & 5,0 & 5,0 & 4,8 & 5,0 & 4,3 & 4,2 & 4,8 & 5,0 \\
\hline - makes participants aware of the importance of effective communication & & & & & & 4,9 & 3,4 & 4,7 & 4,6 & 5,0 & 5,0 \\
\hline - makes participants aware of the importance of team collaboration & & & & & & 5,0 & 2,7 & 5,0 & 4,9 & 2,4 & 2,7 \\
\hline - allows participants to better understand Kanban mechanisms & & & & & & 4,1 & 4,4 & 3,1 & 4,7 & 3,0 & 2,9 \\
\hline
\end{tabular}

\section{CONCLUSIONS}

This paper reports on an Action Research project designed to explore the ways in which collaborative games could benefit Kanban teams. We started by carrying out a survey among three Kanban teams of a world wide aviation IT provider in order to identify deficiencies in their current practices. Each problematic issue was mapped to the affected Open Kanban principle. Based on the survey results, we proposed an extension to Open Kanban, which specifies 12 collaborative games, divided into four categories in compliance with four Open Kanban principles.

The feasibility of our extension was evaluated by three Kanban teams with encouraging results. We found that the adopted games: (1) improved participants' communication, commitment, motivation and creativity; (2) helped the teams understand the main mechanism, values or practices of Open Kanban; (3) produced better results than the standard approach; and (4) were easy to understand and play. Moreover, the teams intended to continue playing the games after the project finished. We hope that the reported experience will encourage other practitioners to implement collaborative games in their projects. Future studies may consider examining other collaborative games or adopting games into other software development processes.

\section{REFERENCES}

[1] Ahmad, M.O., Markkula, J., Oivo, M.: Kanban for software engineering teaching in a software factory learning environment. In: World Transactions on Engineering and Technology Education vol. 12(3), 2014, http://dx.doi.org/10.1109/EDUCON.2014.6826129
[2] Anderson D.J.: Kanban: Successful Evolutionary Change for Your Technology Business. Blue Hole Press, 2010

[3] Baskerville, R., Myers, M.D.: Special issue on action research in information systems: making IS research relevant to practiceforeword. In: MIS Quart 28(3), pp. 329-335, 2004

[4] Davison, P.: Group Warmup and Team Building Activities. 2009

[5] Davison, R.M., Martinsons, M.G., Kock, N.: Principles of Canonical Action Research. In: Inf. Syst. J. 14(1), pp. 65-86, 2004, doi: 10.1111/j.1365-2575.2004.00162.x

[6] Derby, E., Larsen. D.: Agile Retrospectives: Making Good Teams Great. Pragmatic Programmers, 2006

[7] Gonçalves, L., Linders, B.: Getting Value out of Agile Retrospectives: A Toolbox of Retrospective Exercises. Leanpub, 2014

[8] Greaves, K., Laing, S.: Collaboration Games from the Growing Agile Toolbox. Leanpub, 2014

[9] Grenning, J.: Planning Poker or How to avoid analysis paralysis while release planning. In: Renaissance Software Consulting, vol. 3, 2002

[10] Hammarberg, M., Sunden, J.: Kanban in Action. Manning Publications, 2014

[11] Hurtado, J.: Open Kanban. github.com/agilelion/Open-Kanban, 2013

[12] International Institute of Business Analysis (IIBA): Agile Extension to the BABOK ${ }^{\circledR}$ Guide. Toronto, Canada, 2013

[13] Klipp, P.: Getting Started with Kanban. Kanbanery, 2011

[14] Kniberg, H., Skarin, M.: Kanban and Scrum: making the most of both. C4Media Inc, 2010

[15] Nikitina, N., Kajko-Mattsson, M., Stråle, M.: From scrum to scrumban: a case study of a process transition. In: International Conference on Software and System Process, Zurich, Switzerland, 2012, http://dx.doi.org/10.1109/ICSSP.2012.6225959

[16] Rodriguez, P., Markkula, J., Oivo, M., Turula, K.: Survey on agile and lean usage in finnish software industry. In: ACM-IEEE International Symposium on Empirical Software Engineering and Measurement, Lund, Sweden, 2012, doi: 10.1145/2372251.2372275

[17] Trujillo, M.M., Oktaba, H., González, J.C.: Improving Software Projects Inception Phase Using Games: ActiveAction Workshop. In: 9th International Conference on Evaluation of Novel Approaches to Software Engineering (ENASE'14), Lisbon, Portugal, 2014 